\title{
CRITERIA FOR NO-PASSING ZONES
}

JANUARY 1971 - NUMBER 3

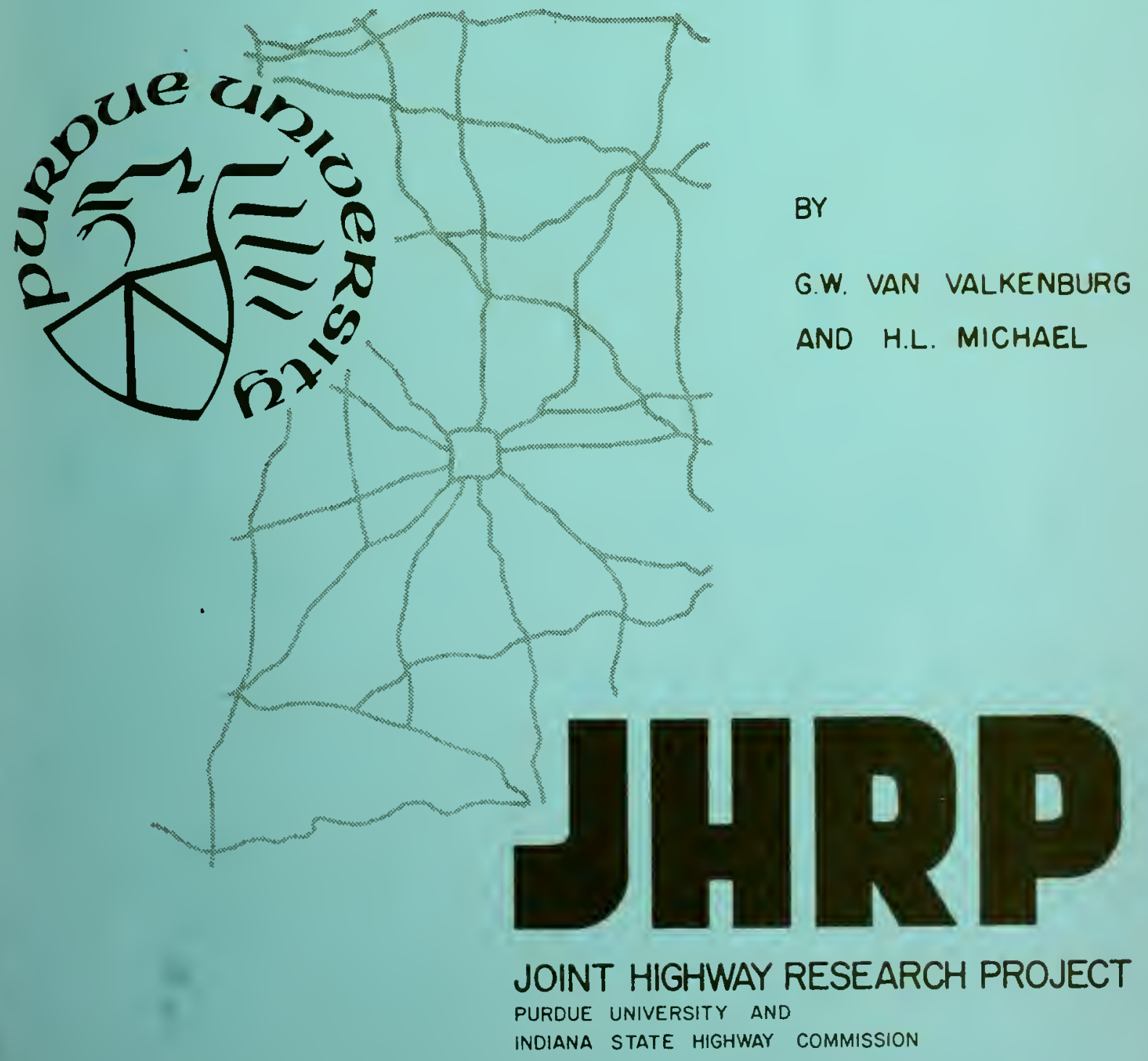




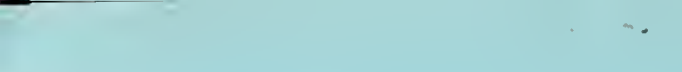


TO: J. F. McLaughlin, Director Joint Highway Research Project

FROM: H. L. Michael, Associate Director Joint Highway Research Project
February 2, 1971

File No: $8-4-32$

Project No: $\mathrm{C}-36-17 \mathrm{FF}$

The attached Technical Paper titled "Criteria for No-Passing Zones" will be presented at the 50th Annual Meeting of the Highway Research Board in January 1971. The paper has been authored by G. W. Van Valkenburg, formerly a Graduate Assistant in Research on our staff, and H. L. Michael. Professor Michael will make the presentation as Mr. Van Valkenburg is in Brazil, South America, and cannot attend the Annual Meeting.

The paper is a summary of the research efforts of $\mathrm{Mr}$. Van Valkenburg on the research project "Warrants, Legislation and Procedure for Establishing No-Passing Zones in Indiana". Professor Michael directed the research. A Final Report on the research has been presented and accepted by the Advisory Board. This Technical Paper will be published by the HRB and approval of such publication is requested.

\section{Respectfully submitted,

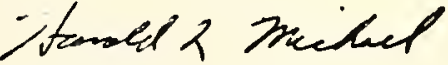 \\ Harold L. Milchael \\ Secretary}

HLM:ms

cc: F. L. Ashbaucher

W. L. Dolch

W. H. Goetz

W. I. Grecco

M. J. Gutzwiller

G. K. Hallock
M. E. Harr

R. H. Harrell

M. I. Hayes

E. M. Mikhail

R. D. Miles

J. W. Miller
C. F. Scholer

M. B. Scott

W. T. Spencer

H. R. J. Walsh

K. B. Woods

E. J. Yoder 
Digitized by the Internet Archive in 2011 with funding from

LYRASIS members and Sloan Foundation; Indiana Department of Transportation 
Technical Paper

CRITERIA FOR NO-PASSING ZONES

by

G. W. Van Valkenburg

Senior Highway and Transportation Engineer

Parsons, Brinckerhoff, Quade \& Douglas

and

Harold I. Michael

Associate Director

Joint Highway Research Project

Purdue University

\author{
File No: $8-4-32$ \\ Project No: C-36-17FF \\ Prepared for presentation at \\ the 1971 Annual Meeting of the \\ Highway Research Board
}

\author{
Purdue University \\ Iafayette, Indiana \\ January, 1971
}


G. W. Van Valkenburg, Senior Highway and Transportation Engineer, Parsons, Brinckerhoff, Quade \& Douglas, and H. L. Michael, Associate Director, Joint Highway Research Project, Purdue University.

\section{A BSTRACT}

The concept presently used by most states for establishing and marking no-passing zones on two-lane highways legally prohibits motorists from driving on the left side of a yellow line throughout the length of a nopassing zone. The shortcomings of this concept, called the short zone concept, are well known. It is physically impossible for motorists to always complete a passing maneuver without crossing the yellow line because of the limited visibility of no-passing zone signs and pavement markings. Furthermore, the crossing of a yellow line to complete a passing maneuver begun prior to the beginning of a no-passing zone is not an unsafe practice. An alternative to the short zone concept is a concept that allows the yellow line to be crossed for the purpose of completing a passing maneuver. This concept, called the long zone concept, prohibits the beginning of a passing maneuver in a marked no-passing zone.

The purpose of this study was to determine which no-passing zone concept should be adopted to assure maximm safety and comfort for the motoring public, and to determine appropriate criteria and legislation to implement the recommended concept. 
The results of the research indicate that the long zone concept, which legally allows the completion of a passing maneuver within a no-passing zone, should be adopted. Criteria for marking no-passing zones and a model law required to implement the concept were developed.

\section{INTRODUCTION}

\section{The Problem}

Despite the present day emphasis on freeways, expressways, superhighways, etc., the bulk of the mural highway network throughout the United States is still the two-lane, two-way highway. At least ninety percent of the total rural mileage is of the two-lane type and much of this mileage was constructed before modern geometric design standards were established. Consequently the horizontal and vertical alignments create hazards that frequently are indirect causes of many accidents.

This contributing factor to accident causation is the limited sight distance which is available on some of these roads due to poor alignment. Sight distance is especially important on two-lane, two-way highways -- more than on four lane highways or freeways -- because the passing maneuver requires the use of the lane normally occupied by on-coming traffic. This constitutes a constant danger to the two-lane highway user.

To reduce this danger, traffic engineers for many years have established and marked no-passing zones with yellow paint and with "Do Not Pass" signs to warn drivers of impending sight restrictions. Laws have also been passed in every state, regulating the behavior of motorists within these zones to preserve the general welfare and safety of the motoring public.

Obviously, warnings of inadequate sight distances for passing on such highways should be clear and motorists should always be certain what such warnings mean. The criteria for establishment of no-passing zones and the 
exact meaning of such markings, however, are not the same everywhere and some confusion does result.

Many states have experimented with the use of additional marking devices to warn of impending no-passing zones. Perhaps the most popular such device is the pennant shaped "NO PASSING ZONE" sign mounted on the left side of the pavement. In 1967 there were three states, Iowa, North Dakota and South Dakota, which were using this sign and numerous other states have been experimenting with it (11). Although the pennant shaped sign is not in the 1961 "Manual on Uniform Traffic Control Devices" (MUTCD), it is included in the draft of a revised edition to be published in 1971.

Other devices which have been studied include a broken yellow line and semi-circular blobs painted on the pavement preceding the solid yellow line. In Great Britain, large arrows have been painted on the pavement to direct traffic back to the proper lane (11).

The problem is realized but the solution has not been found. Usually studies have shown only a small reduction, if any, in the number of violations of the no-passing zone by these additional warning devices (11, 18). Perhaps, traffic engineers have been addressing themselves to the wrong question. Instead of asking how to reduce or prevent violations of the no-passing zone, perhaps the question should be -- is it always dangerous to the motoring public when vehicles cross a yellow line? For example, is it dangerous to pass a farm tractor that is moving $10 \mathrm{~m} . \mathrm{p} . \mathrm{h}$. through a no-passing zone when it is obvious that there is ample distance free of obstructions or oncoming traffic in which to pass? Is it dangerous to finish a passing maneuver within a no-passing zone? Or, is it more dangerous to slam on the brakes when a no-passing zone is seen midway into a passing maneuver or to abruptly swerve in front of a passed vehicle to avoid crossing a yellow line? 
Traffic laws that prohibit driving on the left side of an applicable yellow line throughout its length constitute what is known as the short zone concept. An alternative to this is the long zone concept which prohibits the beginning of a passing maneuver within a no-passing zone.

The short zone concept is contained within the rccommended policy of the "Uniform Vehicle Code" (UVC) and the MUCD. Consequently, most states have laws that incorporate the short zone concept. Only four or five states in 1966 specifically allowed the completion of a passing maneuver within a nopassing zone (10).

\section{Criteria Review}

The 1961 Edition of MUTCD contains criteria or warrants for the establishment of no-passing zones on two-lane and three-lane, two-way highways. The criteria stipulate that when the sight distance is less than a specified amount, a no-passing zone should be established, as shown in Figure 1.

Changes in the MUTCD warrants were proposed in the early discussions for the new MUTCD (2). The proposals were not accepted and the new MUTCD will contain the same minimum sight distances for no passing zones as the 1961 edition. The sight distances are known to be inadequate, however, for safe passing and the problems associated with no-passing zones have made this topic a frequent matter of study and discussion by concerned committees of the American Association of State Highway Officials, the Highway Research Board and the Institute of Traffic Engineers.

\section{Purpose and Scope of Project}

The purpose of this research project was to improve the safety and efficiency of two-lane, two-way highways through improved regulations and 
procedures for establishing no-passing zones. This involved two basic goals as follows:

1. Determine the optimm warrants or criteria for the establishment of no-passing zones at horizontal and vertical curves on two-lane, twoway highways.

2. Determine the necessary legislation to provide a legal and fair basis for the enforcement of restrictions on the passing maneuver, established according to the above warrants.

\section{METHODOLOGY}

Length and Speed of Passing Maneuver

Passing Distance

Two distances are of primary importance in the determination of the sight distance needed to pass another vehicle; the distance traversed by the passing vehicle and the distance traversed by an oncoming vehicle while the passing vehicle is in the "wrong" lane. This second distance is a function of the time needed to complete the passing maneuver which is dependent on the speed and distance traversed by the passing vehicle.

The passing maneuver is illustrated in Figure 2. The first part of the passing maneuver $\left(\mathrm{S}_{\mathrm{O}}\right)$, the distance required to come abreast of the overtaken vehicle, can be disregarded when calculating the minimum sight distance required for establishing no-passing zones. During this phase of the passing maneuver it is still possible to apply the brakes and pull back into the proper lane if an obstruction or oncoming vehicle comes into view. The exact location of this point may vary for each individual and between individuals. This variation may be caused by characteristics of the passing vehicle, the speed of the passed vehicle and/or the speed of an approaching vehicle. 
However, it is generally assumed that this so called "point-of-no-return" occurs when the passing vehicle is abreast or nearly abreast of the vehicle being passed. Based initially on personal judgment and subsequently confirmed through observation, the point chosen for this project occurs where the rear bumper of the passed vehicle is abreast of the middle of the passing vehicle. This point is shown as point $A$ in Figure 2. It is assumed that if a vehicle is at or beyond this point, the driver will determine generally that it is safer and easier to continue and complete the passing maneuver than to apply the brakes and pull back into position behind the vehicle being passed.

The minimum required sight distance to be determined by this research project is considered to be the sum of the following distances, as shown in Figure 2.

$\mathrm{S}_{I}$ - The distance traveled by a passing vehicle between the "point-of-no-return" and the point where it is completely clear of the "wrong" lane used by opposing traffic.

$\mathrm{S}_{2} \quad-$ The distance traversed by an oncoming vehicle while the passing car occupies the "wrong" Iane as described above.

20 feet - An absolute minimum clearance distance between vehicles that would allow the two vehicles to avoid a head-on collision if the other assumptions were all met.

To determine these distances it was necessary to perform extensive field investigations of the passing maneuver. The distance and time taken for passing maneuvers were observed by driving a test car at various speeds over selected sections of mural highways.

\section{Test Roads}

It was assumed that there may be a difference in the length and speed of passing maneuvers on different types of roads. Some of the features of a road 
which might introduce a bias include horizontal and vertical alignment, width and condition of pavement, the number and length of passing zones and the volume and speed of traffic on the road.

Obviously, it was not feasible to test the effect of all possible variables. However, one important variable -- the available sight distance conditions on a road -s could be tested if test roads of different geometric designs were chosen. For this reason, three test roads, each five to six miles long with varying amounts of visual restrictions, were chosen to be test roads. Each test road had two test sections, one in each direction, giving a total of six test sections.

Test Road S. R. 43N, 5.53 miles long, is a portion of state Route 43 located about eight miles north of West Lafayette. The horizontal alignment is generally straight with numerous vertical curves that restrict the sight distance on the southern end. In the northbound and southbound directions, respectively, there are five and four no-passing zones totaling 1.53 miles and 1.40 miles in length. About $28 \%$ of the road has a sight distance of less than 1500 feet.

Test Road S. R. $43 \mathrm{~S}$ is a $6.20 \mathrm{mile}$ portion of State Route 43 located about seven miles south of Iafayette. There are five no-passing zones in each direction totaling 2.72 miles in the northbound direction and 2.82 miles in the southbound direction. About $40 \%$ of the road has a sight distance of less than 1500 feet.

Test Road S.R. 25 is a portion of State Route 25, 5.4 miles long, located northeast of Lafayette. The road has many hills and horizontal curves which restrict sight distance; $63 \%$ of the road has a sight distance of less than 1500 feet. There are eight no-passing zones totaling 1.81 miles in the northbound direction and nine no-passing zones totaling 1.53 miles in the southbound direction. 
Equipment and Personnel

The Test Car used throughout the experiment was a blue, 1962, 4-door Chevrolet sedan owned by Purdue University. A Stewart Warner survey speedometer with an odometer that reads to one-hundredth of a mile ( 52.8 feet) was mounted under the dashboard where it could be seen easily by both the driver and a passenger sitting in the front seat. A stop watch was used to measure the time used during the passing maneuver. The same personnel, consisting of a driver and recorder, were used throughout the experiment.

\section{ExperimentaI Procedure}

Numerous test runs were made by the test vehicle over the test roads to Ineasure the lengths of the passing maneuvers and the time to complete a pass. The odometer was reset to zero at the beginning of each test run at the exact same beginning point for each test section. By doing this the location of each passing maneuver within the test section could be plotted.

The type of vehicle and type of pass were noted for each pass. For instance, a pass by a foreign car, pickup, single unit truck or semi-trailer truck was noted. It was noted also if the finish of a pass maneuver was hurried or forced by the presence of an oncoming vehicle or yellow line. Obviously, this was a judgment factor but in most cases the abrupt unnatural movement of the passing vehicle could be discerned easily.

Test runs were made only when the pavement was dry between the off peak hours of 9:30 a.m. and 3:30 p.m. Monday through Saturday during the months of Jamary, February and March, 1969.

The Speed of the Test Car was maintained constant throughout each test mun. Data were collected for three speedometer readings of the test car .. 40, 50 and $65 \mathrm{mph}$. The actual speed of the test car corresponding to these speedometer readings was 38,47 and $61 \mathrm{~m} . \mathrm{p} . \mathrm{h}$., respectively. These speeds 
span the range of average traffic speeds that are usually found on two-lane, two-way roads during the off peak hours.

The Distance to Pass was determined by taking a reading of the odometer when a vehicle was at the "point-of-no-return" and taking another reading when the back wheels of the test car passed over the point where the left rear wheel of the passing vehicle crossed the centerline. The difference between these two readings gave a close approximation of the distance taken to pas8. The Time to Pass was determined by starting the stop watch when the passing vehicle reached the "point-of-no-return" and stopping it when the passing vehicle crossed the centerline as described above. The decision of when the passing vehicle was at the beginning and ending point of the passing maneuver was made always by the driver of the test car. The driver also operated the stop watch to minimize error due to perception and reaction time. The duty of the recorder was to rend the odometer upon the instruction of the driver and to record the readings.

A Sight Distance Survey was made for each test section with sight distance measured along the centerline of the bighwny. For this survey, the height of eye and target was 3.75 feet above the bighway in accordance with MUTCD criteria.

Speed Studies on the test sections to determine the speed distribution of traffic on each were also made. The location in each case was on a tangent, level portion of the road where there was no restriction to the passing maneuver. This type of location was picked because this is where pasaing maneuvers occur most often. 


\section{EXPERIMENTAL RESULTS AND ANALYSIS OF DATA}

\section{General Observations}

Over three thousand miles were driven to collect data on the length and speed of the passing maneuver. Information on 915 passing maneuvers was recorded over a period of three months. The locations of no-passing zones, passing maneuvers and sight distance were plotted for each of the six test sections. A portion of one of these test sections is shown in Figure 3.

There were frequent violations of the no-passing zones, i.e., the passing vehicle crossed an applicable yellow line at some point. There were 104 known violations ( $12 \%$ of all passes). In addition there were some violations that were not recorded because the point where the pasing vehicle first crossed the centerline when initiating the passing maneuver could not be recorded. It was observed, however, that some vehicles initiated a passing maneuver prior to the end of a no-passing zone, especially when the passed vehicle was traveling at a slow speed and where the no-passing zone had been unduly extended.

It was also observed that traffic did not pass where sight distance was low, whether marked or unmarked. It appears that most drivers do not make $a$ passing maneuver judgment only from the absence of an oncoming vehicle and the absence of a yellow line. If drivers cannot see what they consider to be a safe distance in front of them, they will not initiate a passing maneuver even though there may be no yellow line to warn them. Such a situation occurred most noticeably on test road S. R. $43 \mathrm{~N}$ in the vicinity of station 1.4. In this area there is a horizontal curve which is not marked by a yellow line but motorists do not think they can see far enough to make a safe passing maneuver (maximum sight distance at one point is only 1100 feet). Not a single pass was completed at any speed in this area despite the absence of a no-passing zone. 


\section{The Length and Speed of Passing Maneuvers}

\section{Data Classification}

The Types of Passing Vehicles were separated into four groups; automobiles, pickups, single unit trucks and semi-trailer trucks. The number of passing maneuvers completed by pickups, trucks and semi-trailer trucks totaled 67, 24 and 27, respectively, for all types of passing maneuvers and all roads. A statistical analysis comparing the length and speed of passing maneuvers by these various vehicles was not undertaken because there were not enough observations to warrant conclusions. However, from inspection of the mean lengths and speeds of the passing maneuvers (see Table 1) it is evident that criteria cannot be evolved for all types of vehicles without increasing the lengths of no-passing zones beyond that which would be reasonable or tolerable. Therefore, the statistical analysis was confined to passing maneuvers of automobiles only.

The Types of Passes were separated into four basic categories. An "accelerative pass" was a pass by a motorist who for one reason or another slowed down to the speed of the test car and followed behind the test car before initiating the passing maneuver. A "fly pass" was a pass by a motorist who did not slow down to the speed of the test car but passed the car "on the fly."

"Voluntary return" is a term used to describe the completion of a pass by a motorist when there was nothing forcing him to return to the right hand lane. A "forced return" indicates the opposite, usually being forced by the presence of an approaching vehicle or the beginning of a no-passing zone.

\section{Test Results}

The Mean Length of Passing Maneuvers is show in Table 1 for the four types of passes; accelerative-voluntary return, flying-voluntary return, 


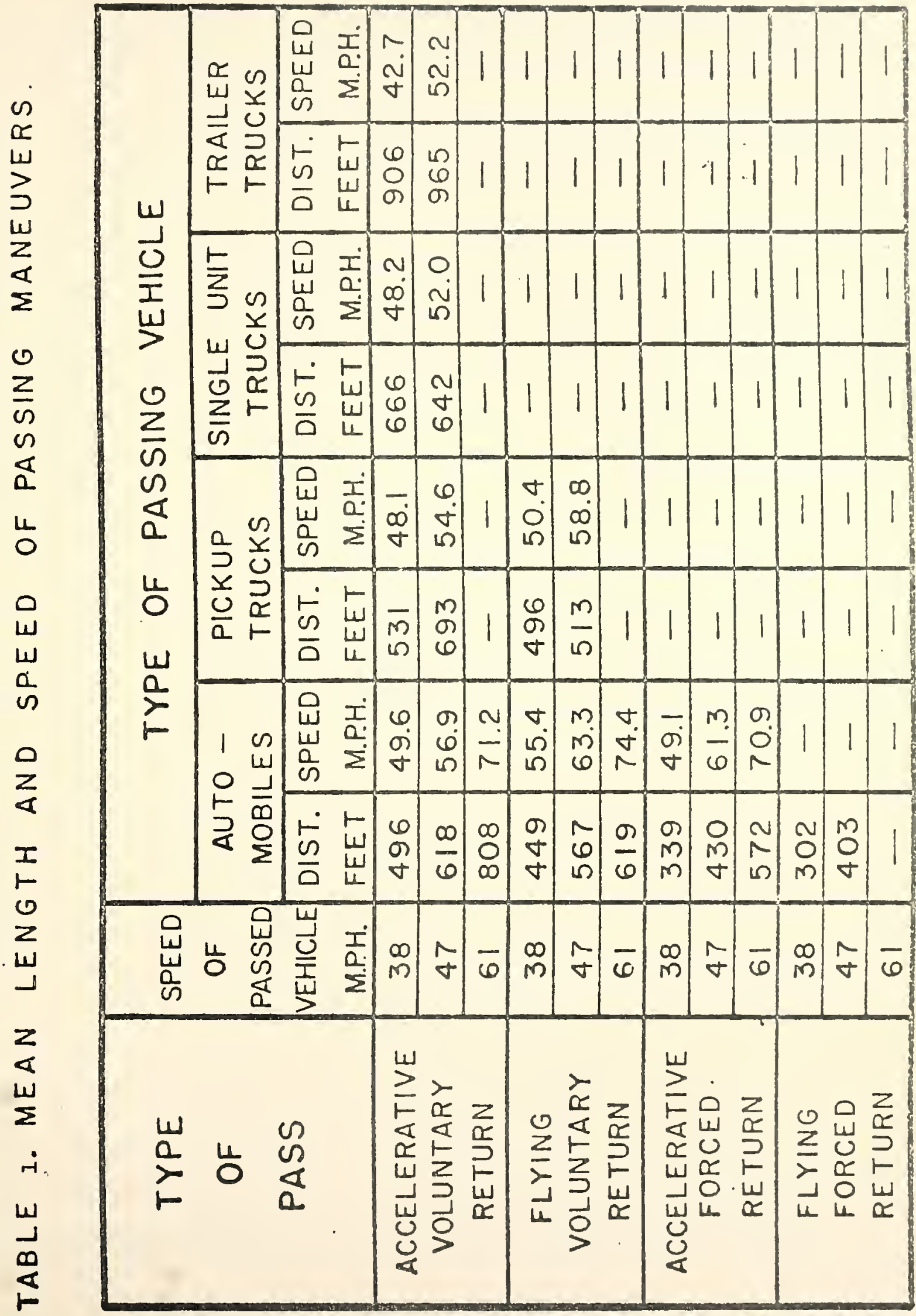


accelerative-forced return and flying-forced return. Of these four types of passes, the mean length of the accelerative pass with a voluntary return by automobiles was consistently longer when passing the test car at speeds of 38,47 , and $61 \mathrm{~m} . \mathrm{p} . \mathrm{h}$. than for the other types of passes. This is illustrated in Figure 4.

The Mean Speed of Passing Vehicles of the various types for the four types of passing maneuvers are also shown in Table 1. A plot of the mean speeds of the passing cars vs. the speeds of the passed cars for three types of passing maneuvers is shown in Figure 5. From this it was apparent that the speed of passing vehicles in an accelerative type of pass with a voluntary return was lower than for other types of passes.

It was concluded, therefore, that both the speed and length of an accelerative-voluntary return type of pass were most critical. Also, this type of pass predominated in occurrence over all others. Therefore, the minimum sight distance requirements were based on the accelerative-voluntary return type of pass.

A Comparison to AASHO Criteria is also shown in Figures 4 and 5. The dashed lines represent the AASHO criteria as taken from "A Policy on Geometric Design of Rural Highways" (4) .

According to AASHO, "Speeds of overtaken vehicles were approximately 10 miles per hour less than speeds of passing vehicles." This was substantiated in this project and is illustrated in Figure 5. The dashed line in Figure 5 is a plot of the speed of the overtaken or passed car vs. the speed of the passing car assuming that the speed of the passing car is 10 miles per hour faster than the passed car. As can be seen the plot of the mean speed of accelerative-voluntary return type of pass nearly coincides with the AASHO plot. 
To compare passing distances, the values of $2 / 3 \mathrm{~d}_{2}$ taken from "A Policy on Geometric Design of Rural Highways" were plotted by subtracting 10 miles per hour from the average passing speed to obtain the average speed of the passed car. This plot, shown by a dashed line in Figure 4 falls very close to the plot of the mean length of the accelerative-voluntary type of pass obtained in this research project. The close proximity of these plots is coincidental, however. The AASHO plot is based on an acceleration pass with a forced or hurried return (느).

The AASHO data were obtained from a study of selected no passing zones by observing passing maneuvers at each from a fixed observation post (5). The procedure used in this research project enabled the collection of data under varying geometric conditions over test roads totaling about 17 miles in length. The AASHO data for the range of 60 to $70 \mathrm{miles}$ per hour for passing vehicles (corresponding to 50 to 60 miles per hour for passed vehicles) is also based on extrapolated values. The results of this research, in addition to substantiating the accuracy of the AASHO data, suggests use of a different type of pass as the basis for no-passing criteria and extends the results to varying geometric conditions and higher passing speeds.

\section{Statistical Analysis}

The purpose of the statistical analyses primarily was to determine if there was a significant difference in mean length to pass on various test roads and at various speeds. Through these analyses it was possible to determine what effects these variables had on the mean lengths and speeds and to place confidence limits on the test results.

An analysis of data within each test road concluded that overall it could be stated with a confidence level of $95 \%$ that there was no significant difference in the lengths of the accelerative-voluntary return type of 
passing maneuver in one direction over the other for a given test road. Test data, therefore, taken in both directions were combined.

Further analysis indicated that the individual test roads did have an effect on the length of the passing maneuver but that it was not practically important. A maximum difference of mean passing distance between roads within the same speeds for the passed vehicle of only .015 mile or about 80 feet was found. On the other hand, the length of the passing maneuver increased significantly as the speed of the overtaken car increased, with a maximum difference of about 315 feet.

Throughout the study, it was the intent to be conservative. Passing maneuvers that were rorced and subsequently mach shorter (at least 150 feet; see Figure 4) than those with a voluntary return were classified separately. On the other hand, passes by motorists who were obviously lazy in returning to the proper lane were included in the voluntary return classification.

It was the intent of this research project to develop criteria that could have a broad application to all roads. To do this, however, it would have been necessary to select a random sample of test roads throughout the United States. Therefore, the criteria, which were developed by cambining data on all three test roads in this study, are theoretically applicable only to roads in the central area of Indiana. However, the statistical analyses indicate that the effect of roads on the length and speed of passing maneuvers is minimal. Therefore, it is suggested that the recommended criteria are sufficiently representative and conservative to be applicable to all roads.

Confidence limits on the mean length and speed of the passing maneuver were computed to provide an idea of how close the computed mean is to the true mean. One can be $95 \%$ confident that the true means of the length and speed of passing maneurers are between the upper and lower limits listed in Tables 
2 and 3. The upper limit is the most important from a safety viewpoint. As can be seen in Table 2, the greater the speed of the overtaken car, the greater the variation in the length of the passing maneuver. The upper confidence limit at 61 miles per hour for all roads combined was atill only .007 mile or 37 feet longer than the mean length. From this it seems apparent that the test results are well within the accuracy necessary to establish safe criteria for no-passing zones.

\section{Speed of Traffic on Test Roads}

The speed studies showed that the mean speeds of traffic did not differ by more than two miles per hour between test roads. The speed distribution curves indicated that about $70 \%$ of the traffic (15th to 85 th percentile) traveled in a speed range of about $20 \mathrm{miles}$ per hour (48 to $68 \mathrm{miles}$ per hour). About $50 \%$ traveled within a range of plus or minus 5 miles per hour of the mean speed of traffic.

The frequency at which a vehicle will be passed is a function of its speed. Considerable passing of vehicles traveling less than the mean speed will likely occur while fewer vehicles traveling above the mean speed will be passed. Therefore it would be conservative -- and in the interest of safety -to base no-passing zone criteria on the sight distance required to pass an automobile traveling at the mean speed of traffic. It must be assumed that drivers who pass a vehicle traveling above the average speed of traffic will realize the danger associated with this pass decision and will exercise appropriate safety precautions.

The speed of the oncoming vehicle (which is out of sight) is an unknown quantity to the driver who is about to pass another vehicle. To base the minimum sight distance requirements on the average speed of oncoming vehicles might be dangerous because half of the approaching vehicles would be traveling 


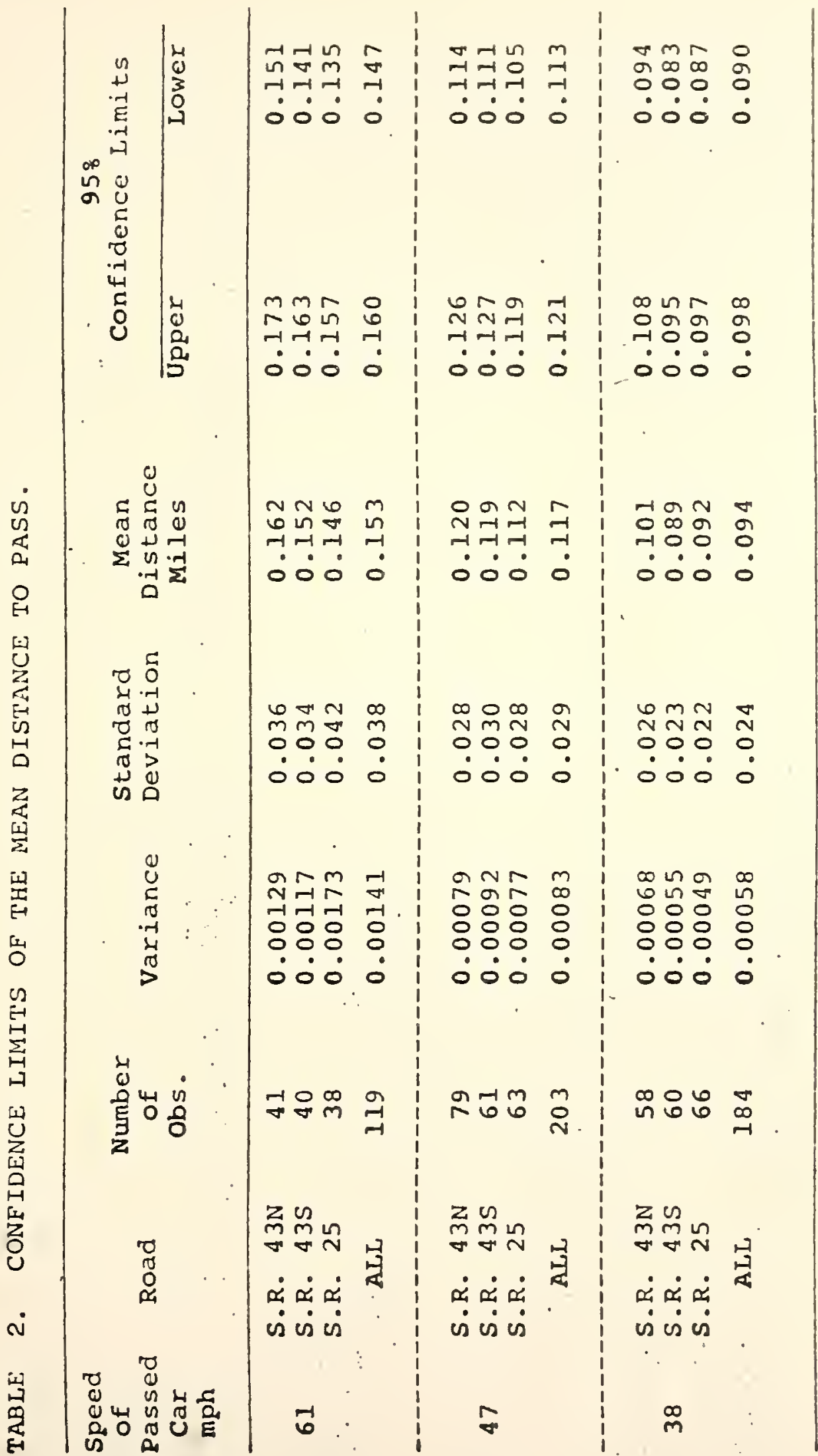




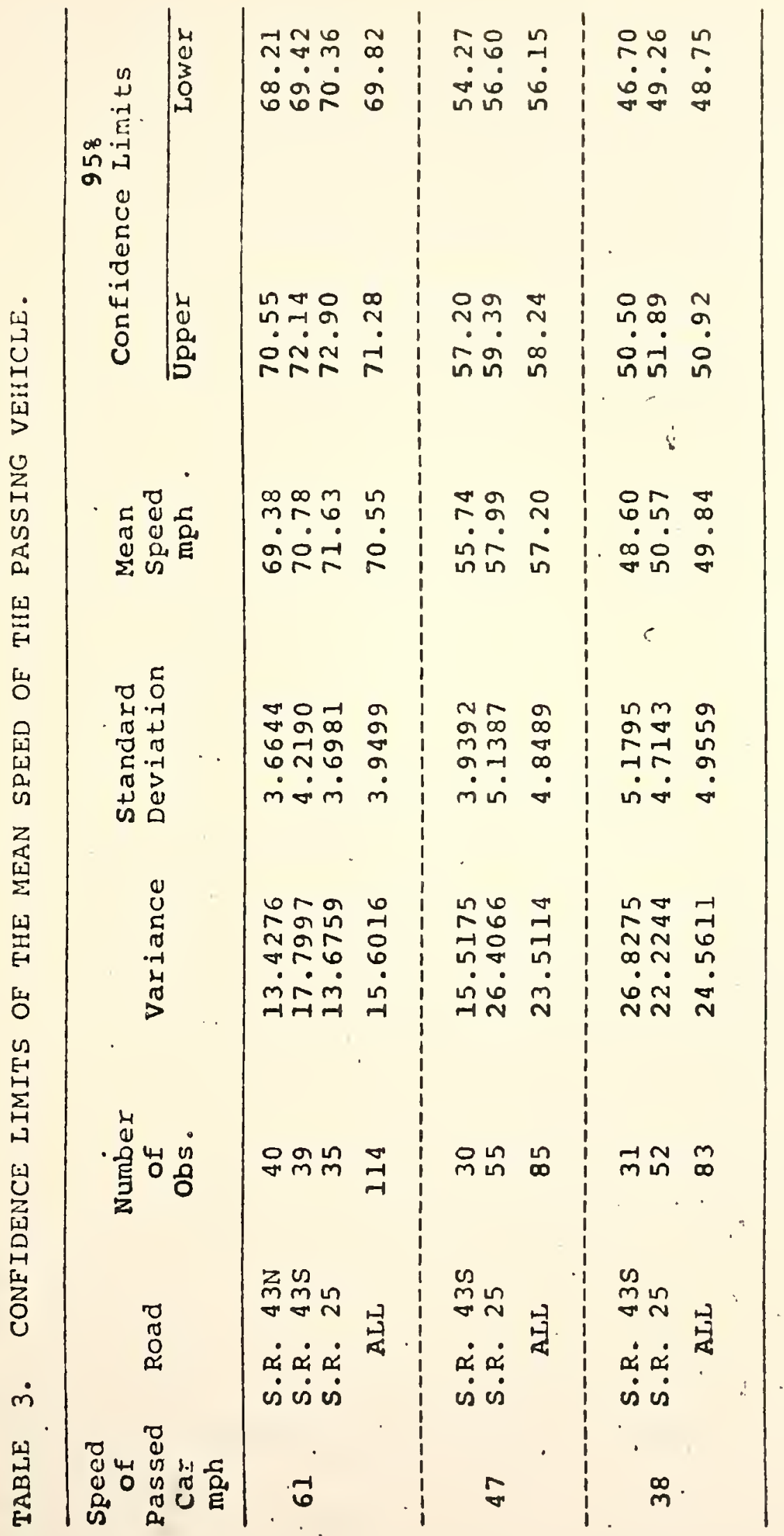


faster than average. Therefore, it seems logical to choose a speed which would include most of the oncoming traffic. Obviously, it is not practical to design for the l00th percentile speed. Therefore, it is simply a matter of judgment as to which speed to choose. The decision is not too critical, however, because the difference in speed between the 85 th and 90 th percentile, for instance, would be only about two miles per hour.

The 85th percentile speed is often used in traffic engineering so this value was chosen for the speed of oncoraing traffic in this study. The 85 th percentile speed varied between five and seven miles per hour above the average speed on the test roads. This is also confirmed by annual speed studies conducted by Purdue University (I). Therefore; a speed of seven miles per hour faster than the average speed of the traffic was used as the speed of the oncoming vehicle.

\section{Minimum Sight Distance}

The minimum sight distance required to safely pass another vehicle is the sum of three distances as follows: $\left(\mathrm{S}_{1}\right)$ the distance to pass; $\left(\mathrm{S}_{2}\right)$ the distance traveled by an oncoming car during that pass; and $\left(\mathrm{S}_{3}\right)$ a clearance between the passing vehicle and the oncoming rehicle. The distance needed to pass and the speed of the passing vehicle has been established and is shown in Figures 4 and 5 . Values were taken from these figures for each incremental speed and by knowing the distance and speed of the passing maneuvers, the duration of the passing maneuvers could be calculated. From this the distance $\left(\mathrm{s}_{2}\right)$ was calculated.

The total resulting minimum required sight distance is plotted in Figure 6. The dashed line indicates extrapolated values outside the limits of this study. 


\section{Comparison with the Criteria of MUTCD}

Both the sight distance criteria according to the 1961 edition of MUCD and an early draft of the proposed new MUTCD are shown in Figure 6 . The MUTCD minimum sight distances are stated for the 85th percentile speed of traffic while the minimum sight distances developed in this research project are for average speed of traffic, the speed of the passed vehicle. As noted previously the 85th percentile speed of traffic on two-lane, two-way state arterial highways. In Indiana is approximately seven miles per hour higher than the average speed. As a consequence the minimum sight distances required by the MUTCD were plotted in Figure 6 at speeds seven miles per hour less than the stated 85 th percentile speeds for comparison with the average speeds us ed in this study. It is apparent that the proposed, but later rejected, MUTCD minimum sight distances coincide with the distances established in this research project.

The proposed new MUTCD draft also is associated with the same regulation as the 1961 MUTCD recommendations concerning the crossing of yellow lines. It is recommended in the MUTCD that an applicable yellow line not be crossed at any time. In effect this extends each no-passing zone by several hundred feet.

As an example, assume a motorist begins to pass a vehicle that is traveling $60 \mathrm{m.p.h}$. and just as his vehicle reaches the "point-of-no-return" he sees a no-passing zone sign ahead. At that moment he has the choice of braking the car to fali back into line or continuing the pass. Assuming that the pass is normal and average as defined in this study, he will need to be approximately 800 feet from the no-passing zone to be able to complete the pass and avoid crossing the yellow Ine (see Figure 4). Ordinarily a no-passing sign can only be seen about 300-400 feet away and a yellow line is 
even less visible. He would most likely be trapped into crossing the yellow Iine and would therepy become an offender of the law.

Many motorists are aware of the law and rather than continue a normal passing maneuver they swerve abruptly in front of the passed car to avoid crossing the yellow line. This unnatural movement was observed frequentiy during this experiment. It was obvious that such a maneuver did not contribute to the safety and pleasure of either the passed or passing motorist and their passengers.

\section{Minimum Distance Between No-Passing Zones}

The minimum distance between no-passing zones that should be allowed without making one continuous zone is stipulated in the 1961 MUTCD as 400 feet. The early proposals for the new MUICD would have increased this distance, especially at higher speeds, in line with requirements of the short zone concept. If this minimm distance were increased, the effect would be to increase further the length of no-passing zones and decrease the legal opportunities to pass slow moving vehicles. Consequently, capacity would be reduced and the frustration of motorists following slow moving vehicles would be increased.

The distance required to initiate a passing maneuver was investigated. Assuming that the initial phase of the passing maneuver is equal to one third of the total distance to pass (as assumed by AASHO), one half of the distance $\mathrm{S}_{1}$ as measured in this study would correspond to the length of the initial phase. This distance represents the average distance that a motorist would need to accelerate and arrive at the "point-of-no-return" if he were watching and waiting for the end of the No-passing zone to appear. These distances were found to vary from 190 feet at $30 \mathrm{~m} \cdot \mathrm{p} . \mathrm{h}$. to 460 feet at $70 \mathrm{~m} . \mathrm{p} . \mathrm{h}$. It appears the existing 400 foot minimum distance is adequate and could even be reduced for slower speeds under the long zone concept. 


\section{CONCLUSIONS AND RECOMMENDATIONS}

The most obvious conclusion reached during this research project was the inadequacy of the short zone concept presently utilized by nearly all of the states. The large number of motorists who illegally cross an applicable yellow line should not all be classed as law offenders. The law is clearly inconsistent with the physical capabilities of the ariver and vehicle. Consequently the law cannot always be obeyed. Such a situation can only contribute to disregard of laws in general and utter frustration for the unfortunate few who are apprehended.

The long zone concept allows the completion of a passing maneuver across the yellow line. If the motorist is so far into the maneuver that a severe braking action is required to stop the maneuver in order to avoid crossing the barrier line, the motorist is allowed to continue the maneuver for by design such a continuation would be safe. The beginning of a no-passing zone becaming visible during a passing maneuver would, however, provide a cautionary warning, similar to the yellow caution light in traffic signals. And just as the yellow caution light, the approach of an applicable no-passing zone during a passing maneuver should demand only safe and reasonable action on the part of the motorist. Enforcement against violators requires no more judgment on the part of law enforcement personnel than the enforcement of traffic signal regulations.

There is another important aspect to the problem that cannot be ignored. Uniformity of traffic laws and criteria throughout the nation is a necessary and desirable goal. It is true that several years will be required before all states would or could change their laws to adopt the long zone no-passing concept. However, the shortcomings of the short zone concept are well known and many individuals will not be convinced that their state should adopt a law that is known to be unsatisfactory. But most important, many motorists either 
are unable or do not want to comply with the short zone concept, as evidenced by the large number of violations of no-passing zones in this study and others (11, 18).

The logical alternative is to allow the applicable yellow line to be crossed for the purpose of finishing a passing maneuver that was well underway before the beginning of a no-passing zone was reached. This can be achieved through the universal adoption of laws and criteria to implement the long zone concept. Criteria and legislation that might be adopted to implement the findings of this research follow. The major changes in the wording of the "Manual on Uniform Traffic Control Devices" and "Uniform Vehicle Code" that are suggested are underlined (except the tabulated values which are also changes ).

\section{Criteria for No-Passing Zones at Curves (MUTCD)}

.... Where centerlines are installed, a curve warrants a no-passing zone and should be so marked where the sight distance is equal to or less than that listed below for the prevailing (off peak) average speed:

\section{Average Speed \\ (off peak) \\ m.p.h.}

30 and under

$3 I-35$

$36-40$

$41-45$

46-50

$5 x-55$

56-60

6I-65

$66-70$
Minimum Passing

Sight Distance

feet

750

900

1050

1200

1300

1450

1600

1750

1900 
The following tabular data indicates the minimum distance between nopassing zone markings necessary for initiation of a passing maneuver:

\begin{tabular}{cc}
\hline $\begin{array}{c}\text { Average Speed } \\
\text { (off peak) } \\
\text { m.p.h. }\end{array}$ & $\begin{array}{c}\text { Minimum Distance } \\
\text { Between Zones } \\
\text { feet }\end{array}$ \\
\hline 30 and under & 250 \\
$31-40$ & 300 \\
$41-50$ & 350 \\
$51-60$ & 400 \\
$61-60$ & 450 \\
\hline
\end{tabular}

Where these minimum distances cannot be provided, the no-passing zone markings should be connected to form one continuous zone.

\section{Iegislation (UVC)}

The following change in the "Uniform Vehicle Code, Section II-307, No Passing Zones, is suggested so that the long zone concept may be incorporated into no-passing zone legislation:

\section{Model Law - No-Passing Zones}

(a) (No change from current wording).

(b) Where signs or markings are in place to define a no-passing zone as set forth in paragraph (a) no driver shall at any time drive on the left side of the roadway within such no-passing zone or on the left side of any pavement striping designed to mark such no-passing zone except for the purpose of safely completing a passing maneuver begun prior to the beginning point of such a zone.

(c) (No change from current wording). 


\section{BIBLIOGRAPHY}

1. Hejal, S. S., "Iraffic Speed Report No. 86," Joint Highway Research Project, Purdue University, Iafayette, Indiana, 1968.

2. National Joint Committee on Uniform Traffic Control Devices, "Manual on Uniform Traffic Control Devices for Streets and Highways, "U. S. Department of Commerce, Washington, D. C., pp. 122-127, 1961.

3. National Joint Conmittee on Uniform Traffic Control Devices, Part III of Draft of New MUTCD, unpublished, pp. 11-15, 1968.

4. American Association of State Highway Officials, "A Policy on Geometric Design of Rural Highways, "AASHO, Washington, D. C., pp. 140-152, 1965.

5. Prisk, C. W., "Pass Practices on Rural Highways," Proceedings, Highway Research Board, 1941.

6. Traffic Research Section, "Review of Driver Eye Height as Related to Registered Passenger Vehicles," Michigan Department of State Highways, unpublished, 1967.

7. National Conmittee on Uniform Traffic Laws and Ordinances, "Uniform Vehicle Code," Washington, D. C., 1968.

8. "Indiana Motor Vehicle Laws", Central Publishing Company, Indianapolis, Indiana, 1965.

9. "Indiana Motor Vehicle Laws, Revised," Central Publishing Company, Indianapolis, Indiana, 1967.

10. National Committee on Uniform Traffic Laws and Ordinances, "Uniform Vehicle Code: Rules of the Road with Statuatory Annotations", Washington, D. C., pp. 192-234, 1967.

11. Kelly, Don C. and Sidnell, John E. D., "The Researchable Aspects of NoPassing Zone Signing and Marking," Department of Civil Engineering, University of Kentucky, Lexington, Kentucky, 1967. 
12. Marshall, F. C., "Determining and Marking No-Passing Zones," Public Works, Vol. 92, No. 2, pp. 76-78, 1966.

13. Traffic Engineering Division, "A PIan and Procedure for Locating NoPassing Zones," Arizona Highway Department, 1962.

14. Bartels, W. J., "No-Passing Zone Procedures," Traffic Engineering, Vol. 28, No. $7, \mathrm{pp} .15-16,1958$.

15. Traffic Division, "A Review of the Criteria for Marking No-Passing Zones," Michigan Department of State Highways, Lansing, Michigan, 1963.

16. Traffic \& Safety Division, "A Review of the Criteria for Marking NoPassing Zones - 1968," Michigan Department of State Highways, unpublished, 1968.

17. Ostle, Bernard, "Statistics in Research," The Iowa State University Press, Ames, Iowa, 1963.

18. Traffic Research Section, "Study of No-Passing Zone Signing," Michigan Department of State Highways, Lansing, Michigan, 1965.

19. Van Valkenburg, G.W., "No-Passing Zones: Criteria, Legislation and Location", Joint Highway Research Project, Research Report No. 19, Purdue University, Lafayette, Indiana, June, 1969. 


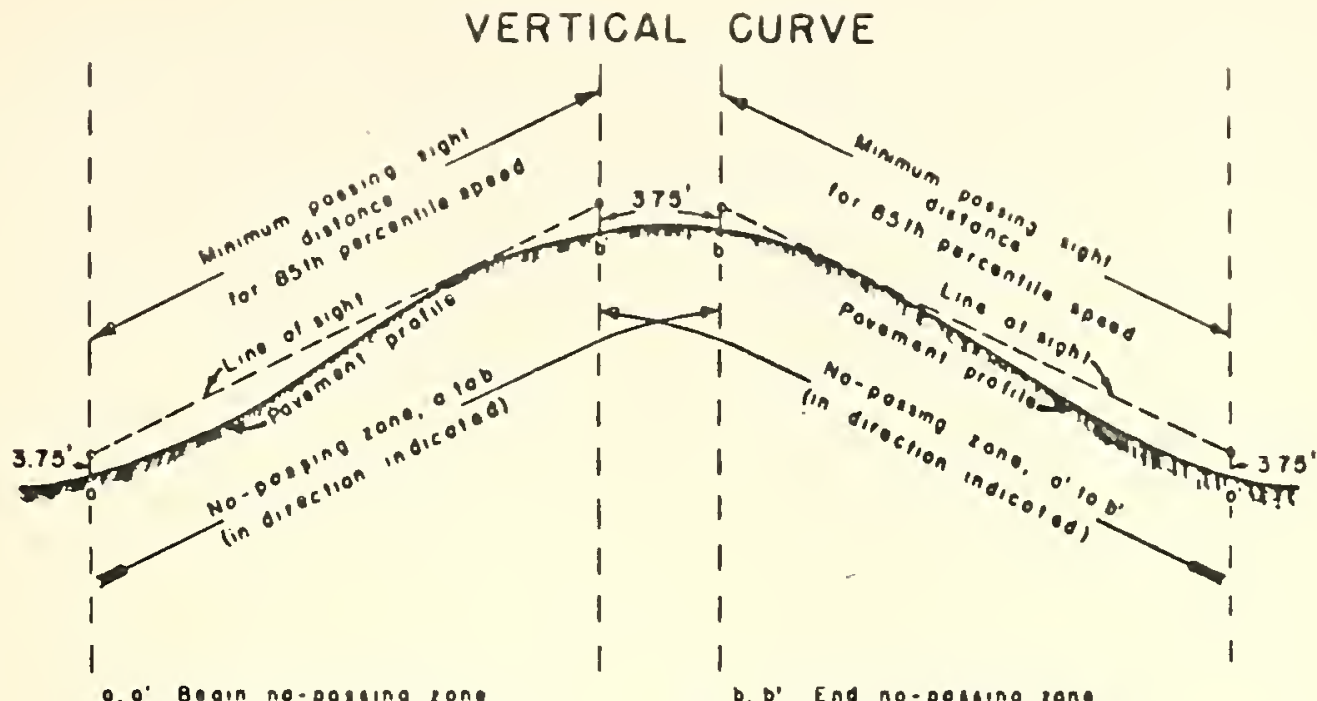

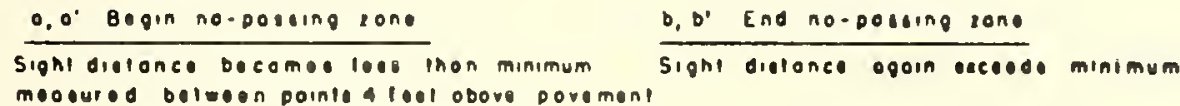

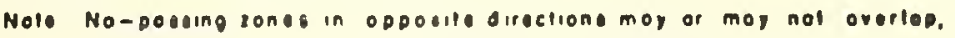

depending on olinement.

\section{HORIZONTAL CURVE}

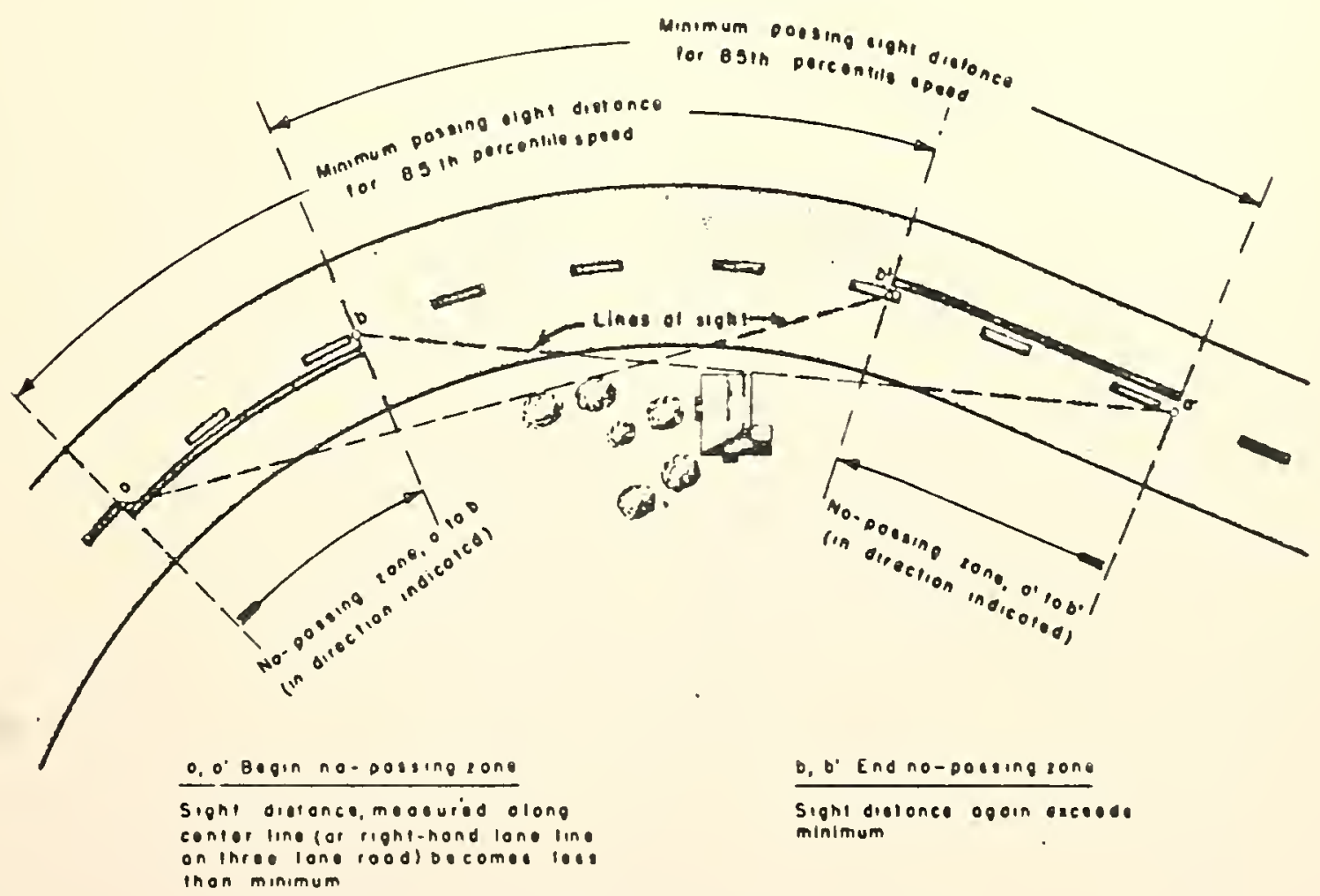

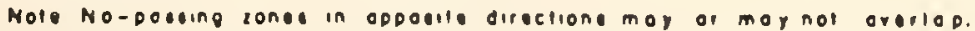

SOURCE: Monual on Uniform Traffic Control Devices.

FIGURE I. DETERMINATION OF NO-PASSING ZONES. 


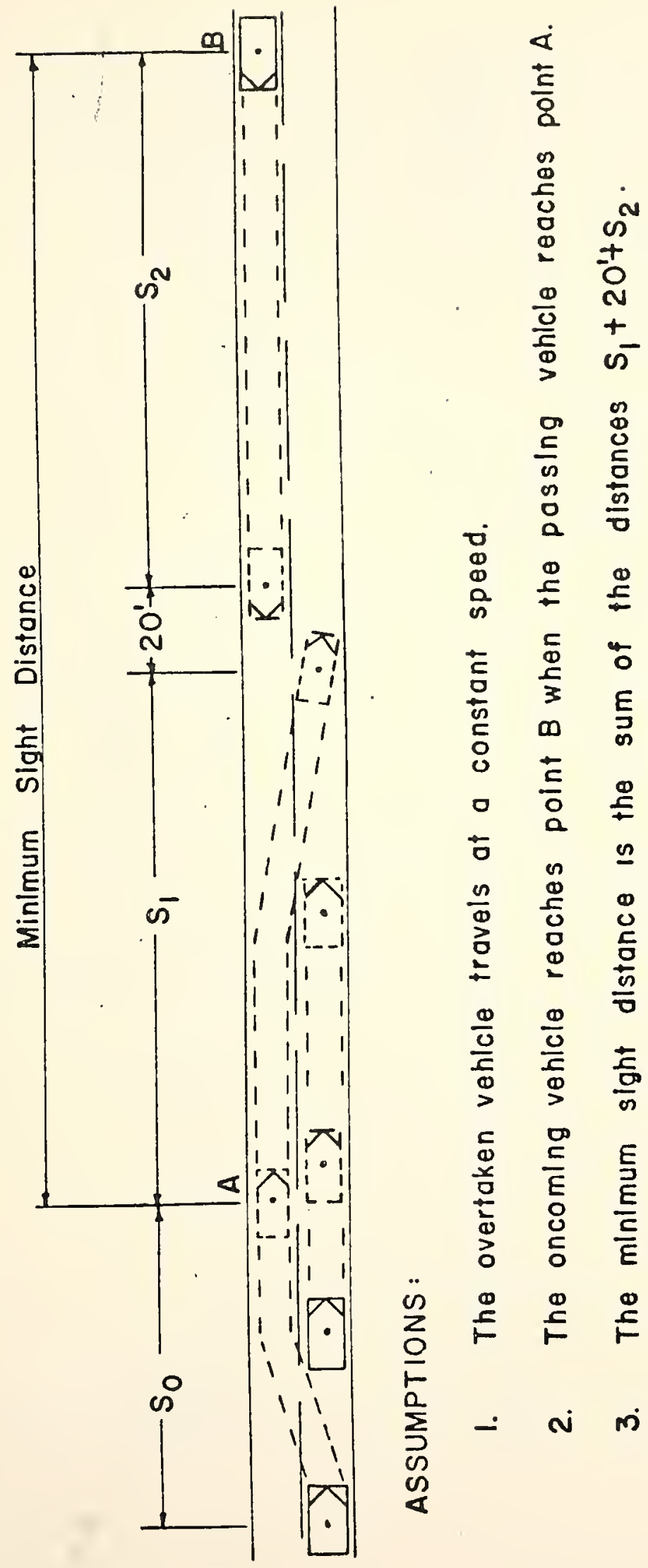

$\alpha$
$w$
$z$
$w$
$z$
$\alpha$
$\Sigma$
0
$z$
$\omega$
$\omega$
$\alpha$
0

I

$\vdash$

N

山

$\stackrel{9}{5}$

$\frac{0}{4}$ 


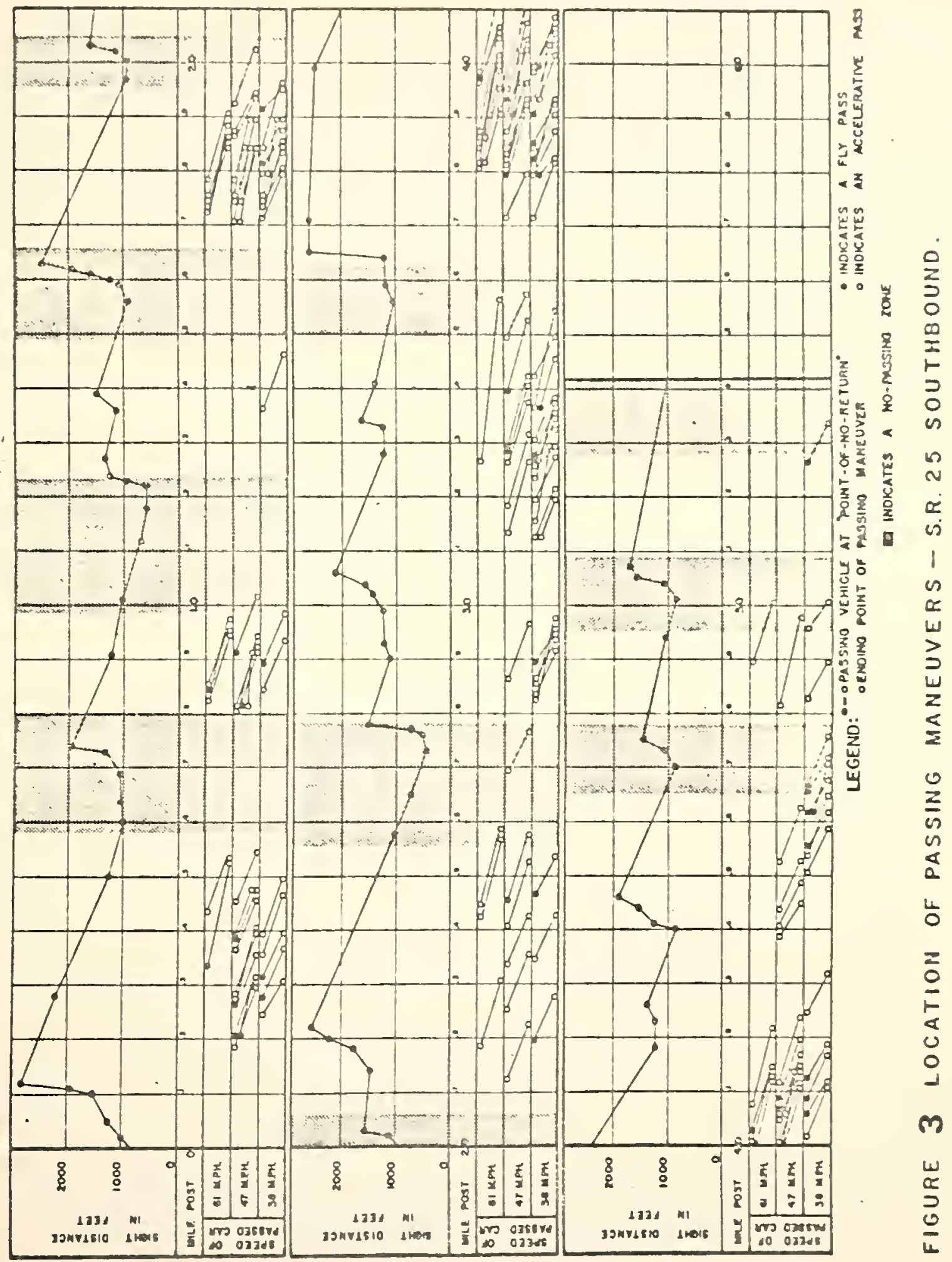




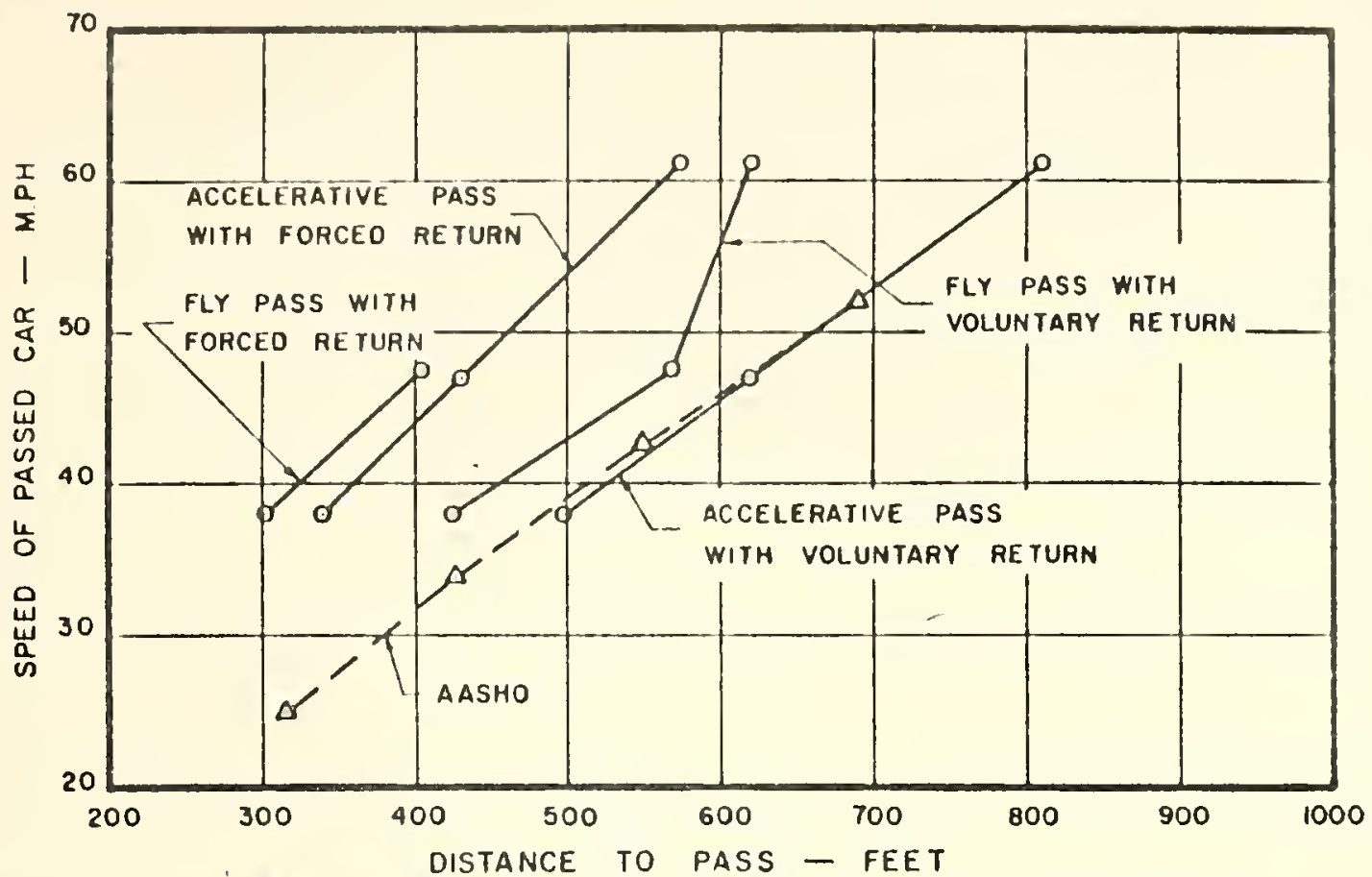

FIGURE 4 LENGTH OF PASSING MANEUVERS.

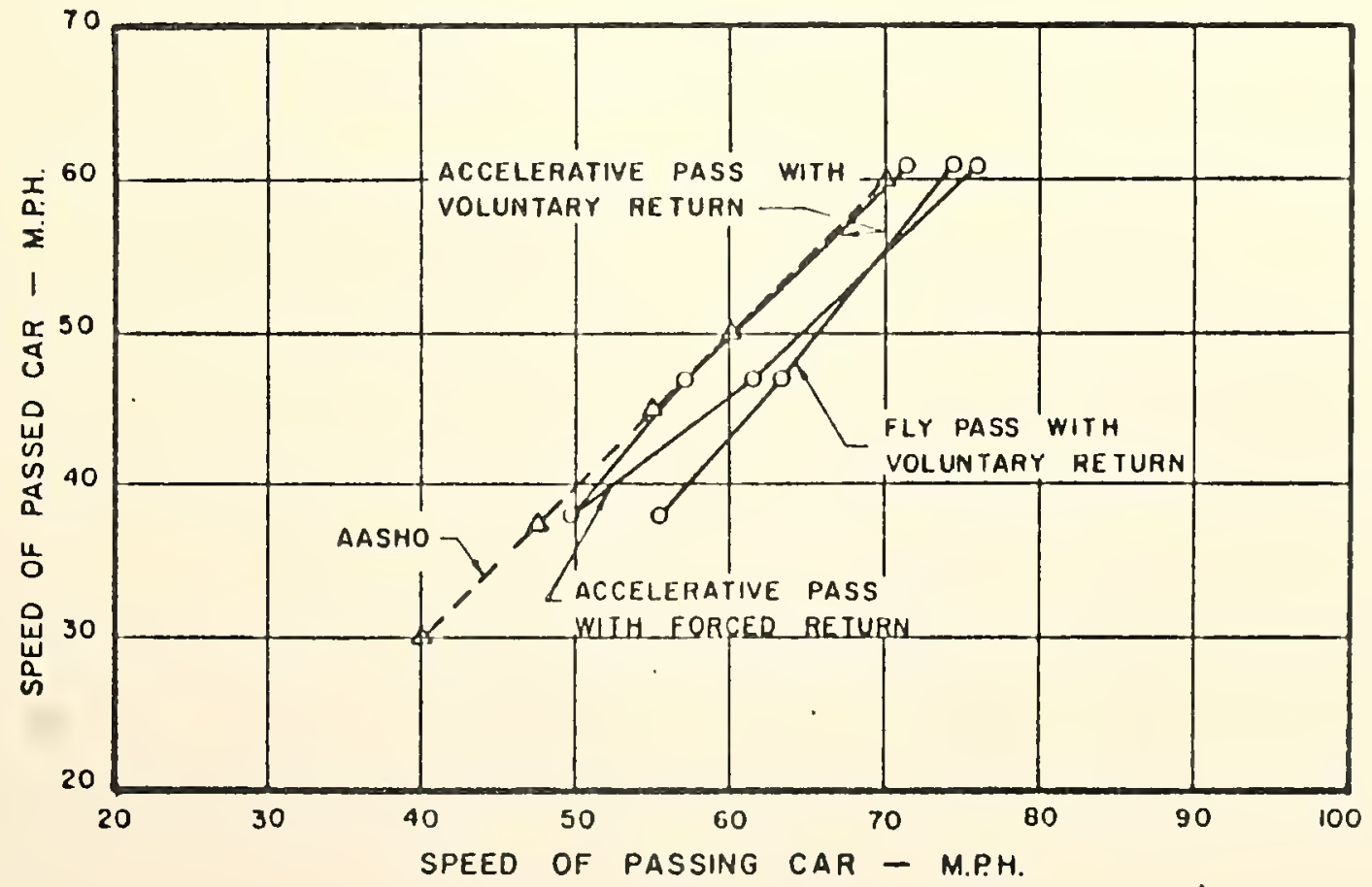

FIGURE 5 SPEED OF PASSING MANEUVERS. 


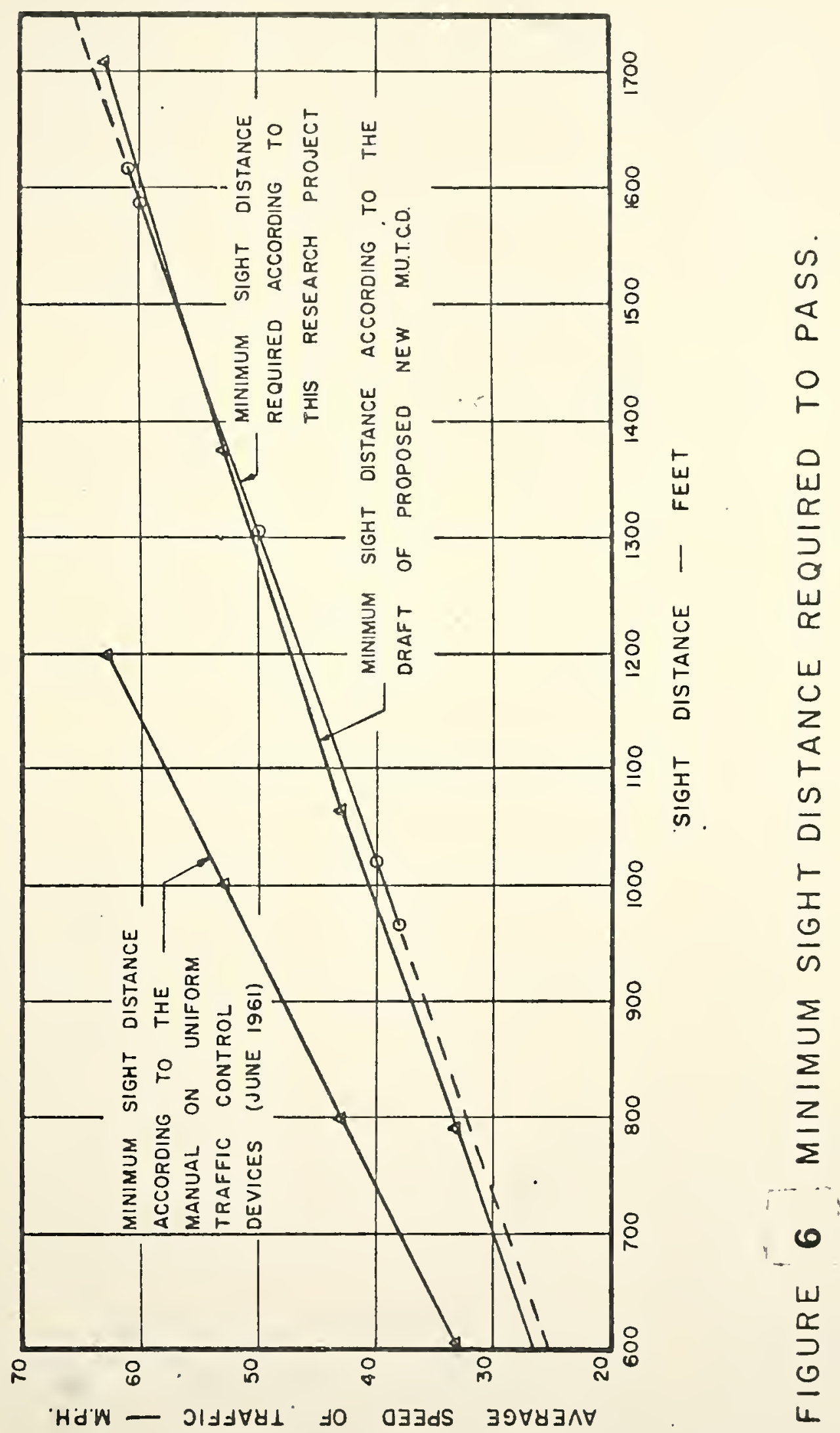



